\title{
Recurrent pain in a child with cerebral palsy: Answers
}

\author{
Andrea Trombetta $^{1} \cdot$ Simone Benvenuto ${ }^{1}$ (i) $\cdot$ Egidio Barbi $^{1,2}$ \\ Received: 7 April 2021 / Accepted: 18 May 2021 / Published online: 29 July 2021 \\ (C) The Author(s) 2021
}

Keywords Child $\cdot$ Abdominal pain $\cdot$ Cerebral palsy $\cdot$ Urinalysis $\cdot$ Struvite stones

\section{Answers}

\section{What is the most likely cause of this child's pain?}

The most likely cause of this child's pain is struvite stones. The patient's history, laboratory tests, and dental and orthopedic evaluations had already ruled out frequent sources of pain for children with cerebral palsy, such as common infections, constipation, abdominal emergencies, caries, bone fractures, and hip dislocation. Children with cerebral palsy are, in general, more prone to be affected by urinary stones, due to several predisposing factors such as hypercalciuria, bone demineralization, dehydration [1], and topiramate treatment for concomitant epilepsy [2]. Struvite stones, in particular, are a subset of kidney stones, composed of magnesium ammonium phosphate (struvite) and calcium carbonate-apatite, which form as a result of urinary tract infections (UTIs) with urease-producing pathogens. It is known that this type of stone is formed quickly, within a few weeks, in the presence of urease-producing bacteria [3], from genera such as Proteus, Providencia, Klebsiella, or Staphylococcus. When the production of ammonia increases and the urine $\mathrm{pH}$ is high, the solubility of phosphate decreases and struvite stones can develop.

\section{How should the diagnostic workup be completed?}

Diagnostic work-up should include urinalysis, kidney and bladder urine culture, and ultrasonography, which can detect

This refers to the article that can be found at https://doi.org/10.1007/ s00467-021-05147-z.

Simone Benvenuto

simone.benvenuto2@icloud.com

1 University of Trieste, Trieste, Italy

2 Institute for Maternal and Child Health - IRCCS "Burlo Garofolo", Trieste, Italy a densely calcified mass, producing marked posterior acoustic shadowing; indeed, a plain radiograph is also able to identify radiopaque images, appearing as branching calcific densities overlying the kidney outline. Stone culture is recommended to identify urease-producing bacteria and direct antibiotic therapy, since bacteria identified by urine culture do not always match those cultured from the stone [4].

\section{What are the best treatment and follow-up for this patient?}

Given the nature of these stones, treatment should include an initial antibiotic regimen, such as amoxicillin-clavulanate or a cephalosporin (e.g., cefixime), before an eventual removal of residual fragments of the stones. Timing and duration of therapy have not been definitively established: 1-2 weeks of oral or gastrostomy administered antibiotics specific for urine culture are recommended, if available, with the addition of broadspectrum parenteral preoperative antibiotics [5]. Remarkably, stone formation inhibitors such as citrate are metabolized by bacteria and as a result are ineffective against struvite stones. After treating the episode, imaging and urine cultures should be repeated within 3 months to confirm stone-free status or identify recurrence [6].

\section{Patient outcome}

Stone analysis showed struvite aggregates. A urine culture was performed, testing positive for Providencia stuartii, a Gram-negative bacteria. Antibiotic treatment with ceftibuten ( $9 \mathrm{mg} / \mathrm{kg} /$ day in a single daily dose) was started for 2 weeks, with no more pain episodes starting from 3 days after. A kidney ultrasound did not reveal any other endoluminal stones and ruled out a pelvic or ureteral dilatation. No additional episodes were noted in the following year, and follow-up ultrasound scans did not reveal vesicoureteral reflux or incomplete bladder emptying. 


\section{Discussion}

The prevalence of struvite stones in children has decreased over the past decades: in France, they accounted for $11 \%$ of all urinary stones in the 1980s and then reduced to $6 \%$ in the 2000s [7]. In a retrospective analysis, Gnessin et al. [8] showed how immobile patients with musculoskeletal anomalies were prone to form struvite stones $(18.4 \%$ vs. $6.2 \%$ in the control group). This event is due to the several risk factors of UTIs in this population, such as incomplete bladder emptying, vesicoureteral reflux, catheterization, and neurogenic bladder [9]. Clinical presentation of struvite stones substantially differs from other stone types: typical renal colic is not always present, while flank or abdominal pain accounts for nearly $70 \%$, followed by fever (26\%) and gross hematuria (18\%) [6]. In the case of struvite staghorn calculi, percutaneous nephrolithotomy is considered the gold standard, while extracorporeal shockwave lithotripsy may be useful in selected cases to avoid the surgical approach, especially in pediatric patients given the higher rate of success compared to adults [10].

Routine prevention of kidney stones includes an adequate fluid intake to reduce urine solute concentration and a low sodium diet with limited animal protein and adequate calcium and potassium intake to reduce urinary calcium excretion [11]. Different options have been proposed to reduce the recurrence rate of struvite stones. One is represented by the use of bacterial urease inhibitors such as acetohydroxamic acid, which decreases urinary alkalinity and ammonia levels even in the presence of infection. Unfortunately, its use has been related to serious adverse effects in $20 \%$ of cases [5], and the drug should not be used in patients with decreased glomerular filtration rate [12]. A dietary regimen with a low phosphorous and low calcium diet in conjunction with oral estrogens and aluminum hydroxide gel consumption has also been suggested to decrease substrate excretion in urine [13]. However, this cumbersome approach carries adverse effects such as constipation and hypercalciuria. A more feasible option is represented by prophylactic antibiotic therapy because of the relationship between persistent UTI and staghorn stone recurrence [14]. However increasing evidence of struvite kidney stones sustained by bacteria resistant to first- and secondgeneration cephalosporins suggests that this approach may be of limited effectiveness in the long term [15]. Intermittent selfcatheterization is associated with lower rates of UTI than an indwelling urethral catheter in patients with neurogenic bladder requiring catheter-based drainage [16].

Urine analysis to detect an infection and kidney and bladder US to rule out stones should be systematically considered in patients with cognitive impairment with unexplained pain.

Some of this paper has been posted on the ResearchSquare preprint server. The preprint can be accessed here: https:// www.researchsquare.com/article/rs-32787/v1.
Acknowledgements The authors thank Martina Bradaschia for the English revision of the manuscript.

Availability of data and materials Not applicable.

Author contribution AT and SB wrote the first draft of the manuscript. EB conceived the work and substantially revised the manuscript. All authors read and approved the final version.

Funding Open access funding provided by Università degli Studi di Trieste within the CRUI-CARE Agreement.

\section{Declarations}

Ethics approval and consent to participate Not applicable.

Consent for publication Not applicable.

Competing interests The authors declare no competing interests.

Open Access This article is licensed under a Creative Commons Attribution 4.0 International License, which permits use, sharing, adaptation, distribution and reproduction in any medium or format, as long as you give appropriate credit to the original author(s) and the source, provide a link to the Creative Commons licence, and indicate if changes were made. The images or other third party material in this article are included in the article's Creative Commons licence, unless indicated otherwise in a credit line to the material. If material is not included in the article's Creative Commons licence and your intended use is not permitted by statutory regulation or exceeds the permitted use, you will need to obtain permission directly from the copyright holder. To view a copy of this licence, visit http://creativecommons.org/licenses/by/4.0/.

\section{References}

1. Hoppe B, Kemper MJ (2010) Diagnostic examination of the child with urolithiasis or nephrocalcinosis. Pediatr Nephrol 25:403-413. https://doi.org/10.1007/s00467-008-1073-X

2. Johnson EK, Lightdale JR, Nelson CP (2013) Risk factors for urolithiasis in gastrostomy tube fed children: a case-control study. Pediatrics 132:e167-e174. https://doi.org/10.1542/peds.2012-2836

3. Flannigan RK, Battison A, De S (2018) Evaluating factors that dictate struvite stone composition: a multi-institutional clinical experience from the EDGE Research Consortium. Can Urol Assoc J 12:131-136. https://doi.org/10.5489/cuaj.4804

4. Shafi H, Shahandeh Z, Heidari B, Sedigiani F, Ramaji AA, Pasha YR, Kassaeian AA, Pasha AA, Mir MM (2013) Bacteriological study and structural composition of staghorn stones removed by the anatrophic nephrolithotomic procedure. Saudi J Kidney Dis Transp1 24:418-423. https://doi.org/10.4103/1319-2442.109623

5. Streem SB, Yost A, Dolmatch B (1997) Combination "sandwich" therapy for extensive renal calculi in 100 consecutive patients: immediate, long-term and stratified results from a 10-year experience. J Urol 158:342-345

6. Flannigan R, Choy W, Chew B, Lange D (2014) Renal struvite stones - pathogenesis, microbiology, and management strategies. Nat Rev Urol 11:333-341. https://doi.org/10.1038/nrurol.2014.99

7. Daudon M, Bouzidi H, Bazin D (2010) Composition and morphology of phosphate stones and their relation with etiology. Urol Res 38:459-467. https://doi.org/10.1007/s00240-010-0320-3 
8. Gnessin E, Mandeville JA, Handa SE, Lingeman JE (2011) Changing composition of renal calculi in patients with musculoskeletal anomalies. J Endourol 25:1519-1523. https://doi.org/10. 1089/end.2010.0698

9. Ost MC, Lee BR (2006) Urolithiasis in patients with spinal cord injuries: risk factors, management, and outcomes. Curr Opin Urol 16:93-99. https://doi.org/10.1097/01.mou.0000193376.07071.ac

10. Orsola A, Diaz I, Caffaratti J, Izquierdo F, Alberola J, Garat JM (1999) Staghorn calculi in children: treatment with monotherapy extracorporeal shock wave lithotripsy. J Urol 162:1229-1233

11. Borghi L, Schianchi T, Meschi T, Guerra A, Allegri F, Maggiore U, Novarini A (2002) Comparison of two diets for the prevention of recurrent stones in idiopathic hypercalciuria. N Engl J Med 346:7784. https://doi.org/10.1056/NEJMoa010369

12. Schwartz BF, Stoller ML (1999) Nonsurgical management of infection-related renal calculi. Urol Clin North Am 26:765-778. https://doi.org/10.1016/s0094-0143(05)70217-2

13. Lavengood RW Jr, Marshall VF (1972) The prevention of renal phosphatic calculi in the presence of infection by the Shorr regimen.
J Urol 108:368-371. https://doi.org/10.1016/s0022-5347(17) 60743-2

14. Martinez-Piñeiro JA, Gaston de Iriarte E, Armero AH (1982) The problem of recurrences and infection after surgical removal of staghorn calculi. Eur Urol 8:94-101. https://doi.org/10.1159/ 000473488

15. Parkhomenko E, De Fazio A, Tran T, Thai J, Blum K, Gupta M (2017) A multi-institutional study of struvite stones: patterns of infection and colonization. J Endourol 31:533-537. https://doi. org/10.1089/end.2016.0885

16. Kinnear N, Barnett D, O'Callaghan M, Horsell K, Gani J, Hennessey D (2020) The impact of catheter-based bladder drainage method on urinary tract infection risk in spinal cord injury and neurogenic bladder: a systematic review. Neurourol Urodyn 39: 854-862. https://doi.org/10.1002/nau.24253

Publisher's note Springer Nature remains neutral with regard to jurisdictional claims in published maps and institutional affiliations. 